
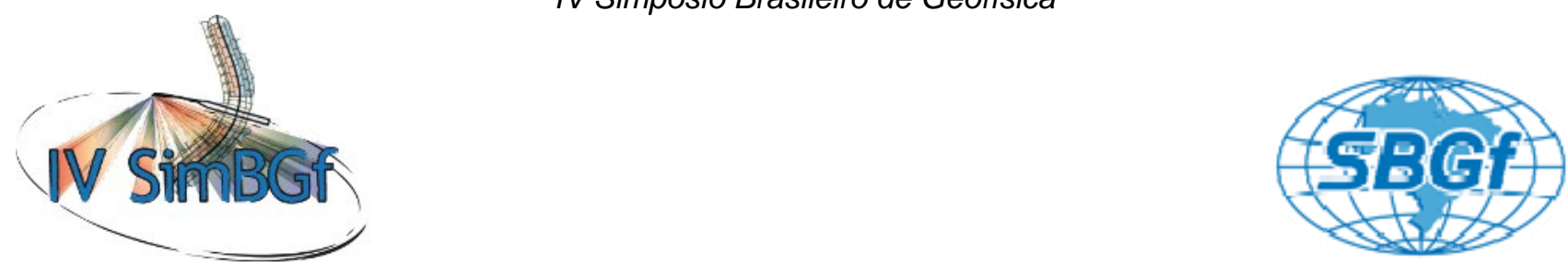

\title{
Aplicação do sonar de varredura lateral para o reconhecimento de vestígios da Vila Amauri no Lago Paranoá (Brasília/DF)
}

IANNIRUBERTO ${ }^{1}$, Marco; ROCHA ${ }^{1}$, Amanda Almeida; DAMACENO ${ }^{1}$, Juliana Garrido; CARNEIRO ${ }^{1}$, Kayque Bergamaschi Rodrigues.

${ }^{1}$ Universidade de Brasília, Instituto de Geociências, Campus Universitário Darcy Ribeiro, 71900-000, Brasília/DF, Brasil

Copyright 2010, SBGf - Sociedade Brasileira de Geofísica

Este texto foi preparado para a apresentação no IV Simpósio Brasileiro de Geofísica, Brasília, 14 a 17 de novembro de 2010. Seu conteúdo foi revisado pelo Comitê Técnico do IV SimBGf, mas não necessariamente representa a opinião da SBGf ou de seus associados. É proibida a reprodução total ou parcial deste material para propósitos comerciais sem prévia autorização da SBGf.

\section{Resumo}

A side-scan sonar survey was carried out in the Paranoá Lake (Brasilia/DF) with the aim of localizing Vila Amauri, a settling of families of workers, who participated to the construction of Brasilia in the late 50', that was inundated with formation of the artificial lake. Result showed morphologic features interpreted as remains of the few masonry structures present in the settling, as well as other anthropic features and possible remains of vegetation.

\section{Introdução}

Após a inauguração de Brasília, em 1960, e com o final de algumas obras da construção civil, iniciou-se um processo de erradicação dos acampamentos provisórios montados pela Novacap para a construção da cidade e das muitas invasões que já existiam naquela época, no intuito de evitar a formação de favelas (Quinto Junior e Iwakami, 1991). A Vila Amauri era uma dessas invasões que deveriam ser erradicadas. Ela estava situada numa área próxima a Vila Planalto, as margens do Ribeirão Bananal, e foi inundada pelas águas do Lago Paranoá, em formação na época.

Segundo o censo realizado na época pelo IBGE (IBGE, 1959), a Vila Amauri tinha 6200 moradores, sendo que $82 \%$ das habitações do assentamento eram barracos realizados com materiais de sobra, resíduos de obras e madeira sem acabamento; além disso, cerca de $72 \%$ não tinha fornecimento de água corrente, $70 \%$ não tinha nenhum tipo de esgoto além de simples fossas e $95 \%$ não tinha eletricidade.

O movimento para transferência da população que habitava a Vila Amauri foi iniciado em torno de uma associação liderada por Amauri de Almeida, funcionário da Novacap. O movimento reivindicava que a Novacap autorizasse e patrocinasse a transferência dos moradores da Vila Amauri para Taguatinga, uma cidadesatélite de Brasília, pois os moradores não tinham condição econômica para arcar com as despesas da mudança (Holston, 1989). Mas, como em Taguatinga, criada em 1958, já não existiam mais lotes disponíveis após seis meses de sua inauguração, os moradores da Vila Amauri foram transferidos para Sobradinho.

No ano de 2010, com o decorrer do aniversario de 50 anos da Capital Federal, algumas reportagens foram realizadas pela mídia (como a TV Globo: http://g1.globo.com/brasil/noticia/2010/04/lugaronde-hoje-e-o-lago-paranoa-foi-uma-vila-naconstrucao-de-brasilia.html) com entrevista a mergulhadores que utilizam as ruínas da Vila Amauri como atrativo e diversão.

Pensou-se, portanto, em se utilizar métodos da geofísica subaquática para realizar um mapeamento da área de interesse com o fim de identificar a posição exata e a extensão das estruturas da vila, visando contribuir para o resgate de uma parte do patrimônio histórico de Brasília.

\section{Metodologia/ Problema Investigado}

O método escolhido para a detecção e mapeamento do alvo foi a sonografia subaquática, que desfruta a reflexão e espalhamento de ondas acústicas para detectar estruturas morfológicas e litológicas no fundo de áreas submersas.

O sensor escolhido para o levantamento foi o sonar de varredura lateral, pela sua versatilidade de uso em mapeamento de feições do fundo de áreas submersas, podendo ser utilizado tanto para levantamentos ambientais, como por exemplo em áreas recifais (Pereira de Souza, 2005), quanto para arqueologia subaquática (Hobbs et al, 1994; Bava de Camargo, 2006).

O Sonar de Varredura Lateral utilizado foi o modelo Edgetech 4100 portátil com sensor TD272 de dupla freqüência $100-400 \mathrm{kHz}$, com resolução de $0,5-1,2^{\circ}$ e seleção de varredura lateral entre 25 e $400 \mathrm{~m}$. Para o posicionamento do barco e dos sensores foi utilizado um GPS com correções diferenciais Omnistar HP (acurácia de cerca de $10 \mathrm{~cm}$ ), conectado com o sonar de varredura e com o software de navegação Hypack. A figura 1 ilustra a configuração do sistema utilizado para o levantamento. O planejamento do levantamento foi baseado na posição indicativa da Vila Amauri, na enseada entre o late Clube e o destacamento da Marinha (Clube dos Fuzileiros Navais), nas margens do Lago Paranoá. Não existindo registros certos da localização do sitio de interesse, foram coletadas informações junto ao Corpo de Bombeiros e relatos falados de mergulhadores e exmoradores (Globo Comunidade, 2010).

$\mathrm{Na}$ definição da estratégia de busca, foram definidos dois planos de navegação, um primeiro para reconhecimento geral da área, com espaçamento das linhas de navegação de $150 \mathrm{~m}$, e outro para levantamento de detalhe, com espaçamento das linhas de $75 \mathrm{~m}$. Na primeira fase do levantamento, o sonar de varredura foi configurado para operar em baixa frequência $(100 \mathrm{kHz})$, 
com varredura de $100 \mathrm{~m}$ por canal, e na segunda fase para operar com a alta frequência $(400 \mathrm{kHz})$, com varredura de $50 \mathrm{~m}$ por canal. No total foram realizadas 4 linhas de reconhecimento e 8 linhas de detalhe. As distâncias relativas entre os sensores instalados foram medidas e inseridas no sistema de navegação para permitir o posicionamento acurado em tempo real.

\section{Resultados}

Os registros sonográficos do levantamento foram processados com o software SonarWiz da Chesapeake Technology, que permitiu a hortorretificação e georreferenciação dos registros, bem como a compensação das perdas transmissivas mediante aplicação de ganhos.

O resultado do processamento foram duas imagens representando a morfologia e a litologia superficial do fundo da área, sendo que a imagem obtida na fase de reconhecimento, utilizando a baixa frequência, foi utilizada somente para a delimitação da área de interesse. A imagem de alta frequência (figura 3), de maior resolução espacial, representa em escala de cinza a morfologia do fundo, a litologia superficial e a presença de alvos de interesse evidenciados como feições de alta reflexão ou retroespalhamento dos pulsos acústicos.

O levantamento permitiu evidenciar algumas feições superficiais da área, algumas de origem natural e outras de provável origem antrópica. Entre as que foram classificadas como naturais, é possível observar o leito das drenagens (córrego do Bananal) - feição sinuosa contornando a parte central da figura, prováveis restos de vegetação rasteira - que se apresentam como manchas escuras na região leste da figura. Entre as feições interpretadas como de origem antrópica encontram-se feições alongadas na região noroeste da figura provavelmente troncos de árvores cortadas, feições arredondadas na parte central da figura - interpretadas como prováveis acúmulos de terra, e duas áreas que parecem apresentar vestígios do assentamento. As seguintes imagens (figuras $4 a$ e $4 b$ ) mostram um detalhe destas duas regiões: na primeira (4a), aparecem feições retas, interpretadas como muros divisórios de lotes ou paredes; na segunda área (4b), situada no cruzamento do que parece ser duas estradas e uma drenagem, as feições não aparecem muito claras, mas sugerem a presença de estruturas antrópicas, provavelmente vestígios de um assentamento humano.

\section{Discussão e Conclusões}

Foi possível localizar na Internet uma antiga, e provavelmente a única, foto (figura 5) da Vila Amauri antes da remoção do assentamento e inundação pelas águas do Lago Paranoá. De acordo com a foto e o censo do IBGE, a área da vila aparece grande relativamente ao tamanho dos vestígios encontrados no levantamento. Segundo a notícia exibida no Globo Comunidade no dia $25 / 04 / 10$, os mergulhadores encontraram "paredes que tombaram com o tempo, tijolos intactos, pisos das casas, garrafas, panelas, sapatos, etc., são alguns desses objetos, pois na época não houve preocupação do governo em limpar a área antes de ser alagada".
Evidentemente, no processo de evacuação do assentamento, boa parte dos materiais reaproveitáveis foi retirada, as casas desmontadas e provavelmente somente as estruturas em alvenaria ficaram no local. Restos de madeiras devem ter sido despejadas nas proximidades da Vila, talvez na área logo a noroeste dos vestígios indicados na figura $4 a$.

Pretende-se, num futuro próximo, estender a pesquisa para abranger as áreas próximas ao fim de localizar outros vestígios e realizar alguns mergulhos para confirmar os resultados obtidos com os sensores acústicos.

\section{Agradecimentos}

Agradecemos a Profa. Roberta Vidotti, pelo incentivo e organização do levantamento, a Direção do late Clube de Brasília por ter disponibilizado a embarcação e o apóio logístico, e o mestre engenheiro Paulo Henrique B. J. Menezes pelo suporte no geoprocessamento dos dados.

O levantamento foi realizado com equipamentos adquiridos no âmbito do projeto "Levantamentos Hidrográficos e Cartografia Eletrônica para Segurança da Navegação em Hidrovias", financiado pela FINEP, fundo CT-Aquaviário.

\section{Referências}

Bava de Camargo, P. F. 2006. Arqueologia da fortificação oitocentista da ponta da Trincheira, barra de Cananéia, SP. Rev. do Museu de Arqueologia e Etnologia, São Paulo, 15-16: 271-290.

Globo Comunidade. 20101. Reportagem exibida no dia 25/04/2010, acesso em 13/07/2010 as 19:08h, http://video.globo.com/Videos/Player/Noticias/0, , Gl M1252851-7823BRASILIA+E+CERCADA+DE+MITOS+E+VERDAD ES,00.html ;13/07/2010; 19:08h.

Hobbs, C. H. III, Blanton, D. B., Gammisch, R. A., Broadwater, J., 1994. A Marine Archaeological Reconnaissance Using Side-Scan Sonar, Jamestown Island, Virginia, U.S.A. Journal of Coastal Research, Vol. 10, No. 2 (Spring, 1994), pp. 351-359.

Holston, J.. 1989. The Modernist City: An Anthropological Critique of Brasilia. University of Chicago Press, page 341

IBGE. Censo experimental de Brasília: população, habitação. 1959

Pereira de Souza, L. A., Leão de Moura, R.. 2005. Aplicações do Sonar de Varredura Lateral para planejamento ambiental em áreas recifais: o exemplo do Banco dos Abrolhos, BA. $9^{\circ}$ Congresso Internacional da Sociedade Brasileira de Geofísica, Salvador, Brasil, 1114 Setembro de 2005.

Quinto Junior, L. P. e Iwakami, L. N.. O Canteiro de Obras da cidade planejada e o fator da aglomeração. In: A Conquista da Cidade. Org. Aldo Paviani. Brasília: UnB/FUB, 1991. 


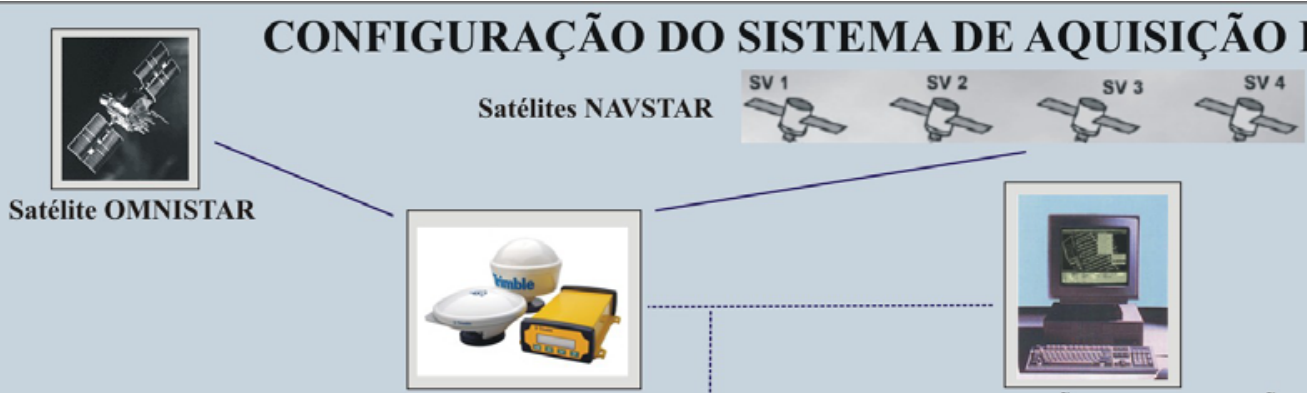

WADGPS TRIMBLE DSM 232

SISTEMA DE AQUISIÇÃO E NAVEGAÇÃO HYPACK

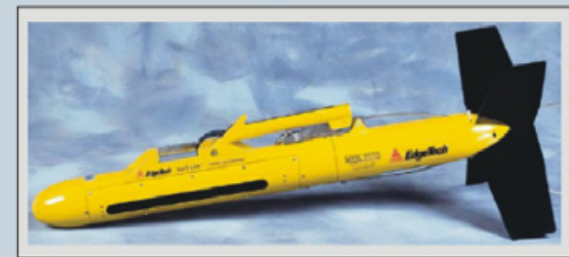

SONAR DE VARREDURA LATERAL EDGETECH 4100P / TD272

Figura 1 - Sistema de aquisição dos dados sonográficos.

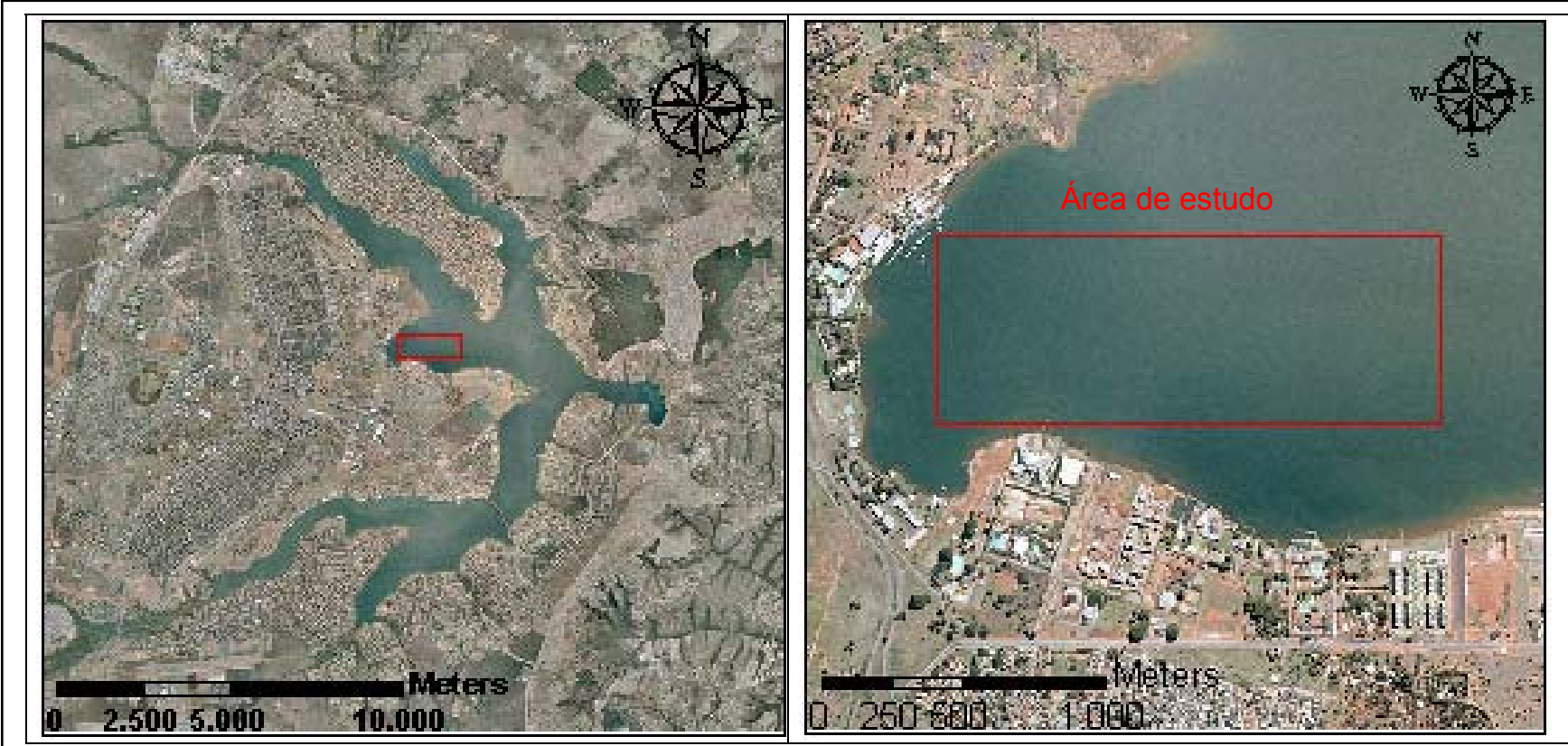

Figura 2 - Localização da área de estudo, nas margens do Lago Paranoá. 


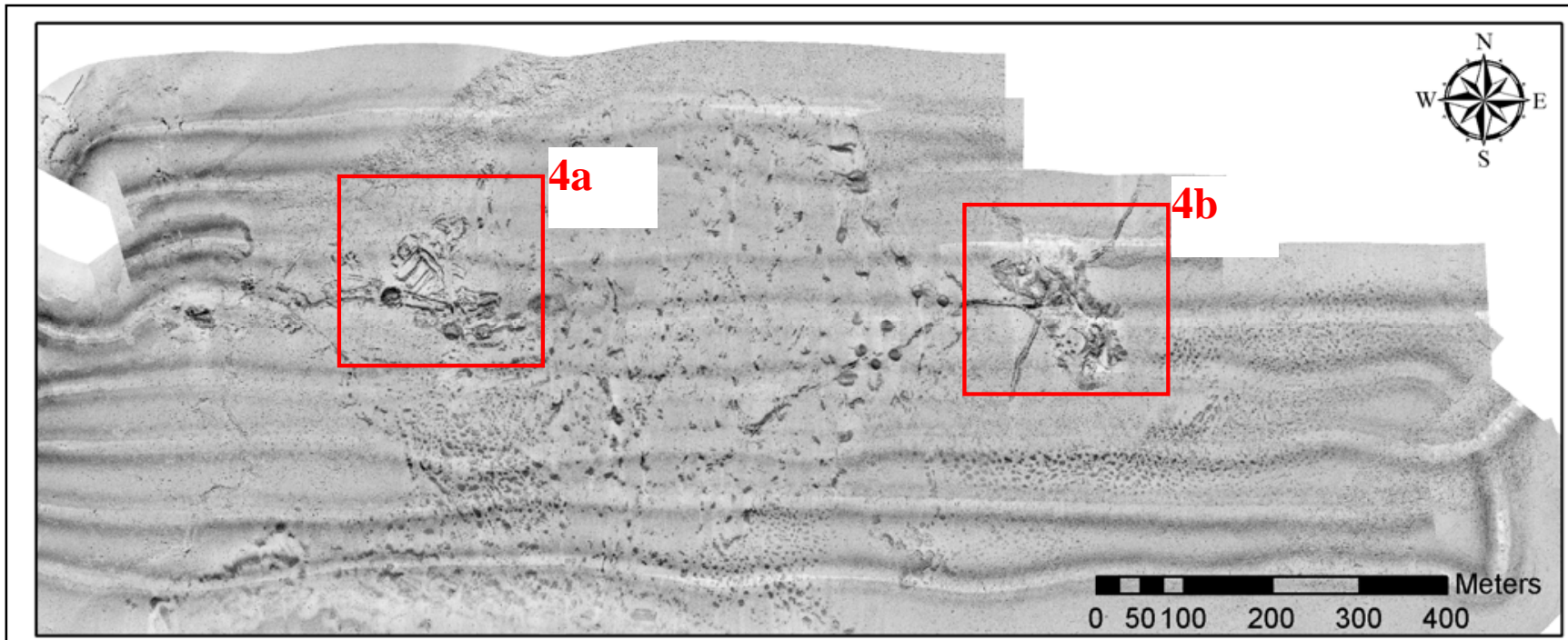

Figura 3 - Mosaico dos registros sonográficos de alta frequência, com indicação das áreas com presença dos alvos interpretados como vestígios da Vila Amauri.

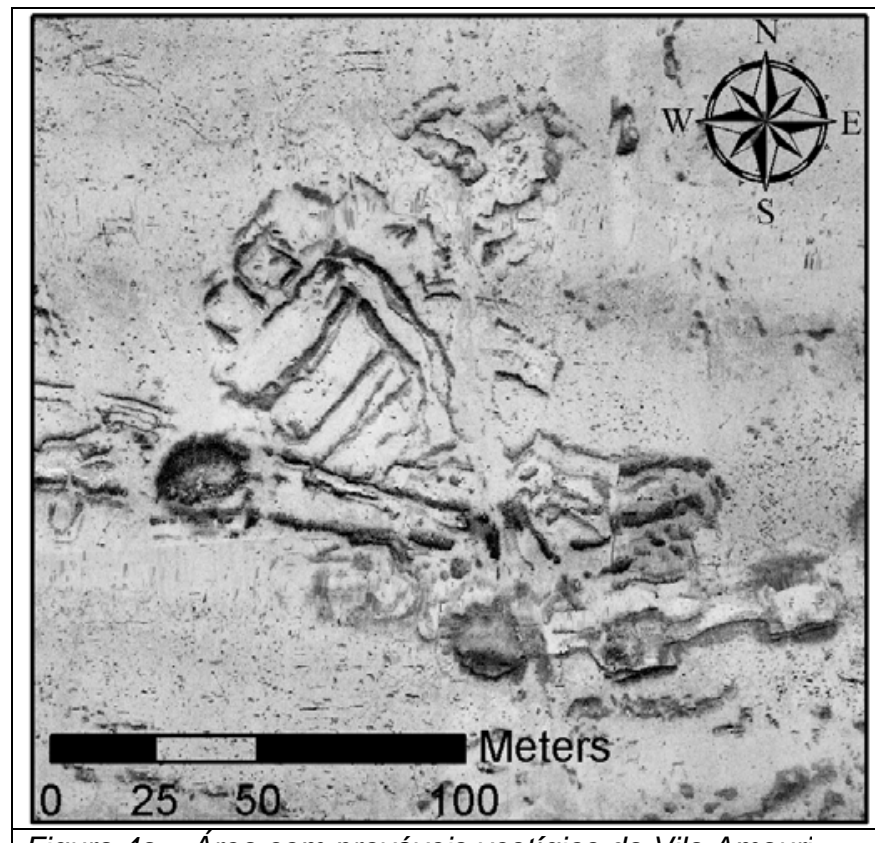

Figura 4a - Área com prováveis vestígios da Vila Amauri

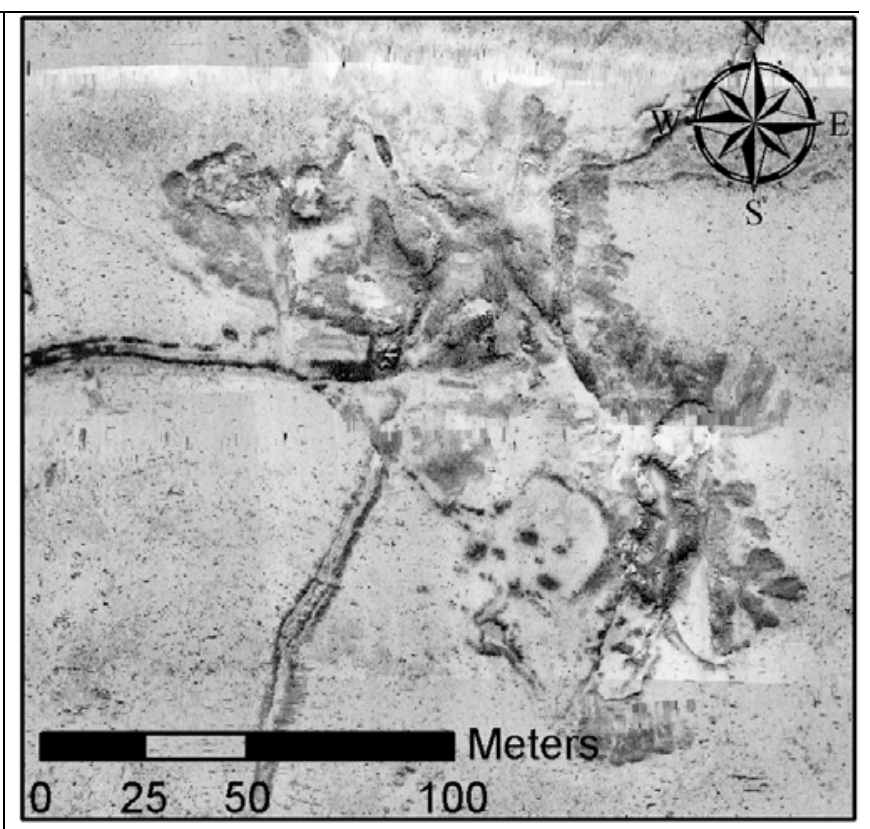

Figura $4 b$ - Área com prováveis vestígios de assentamento 


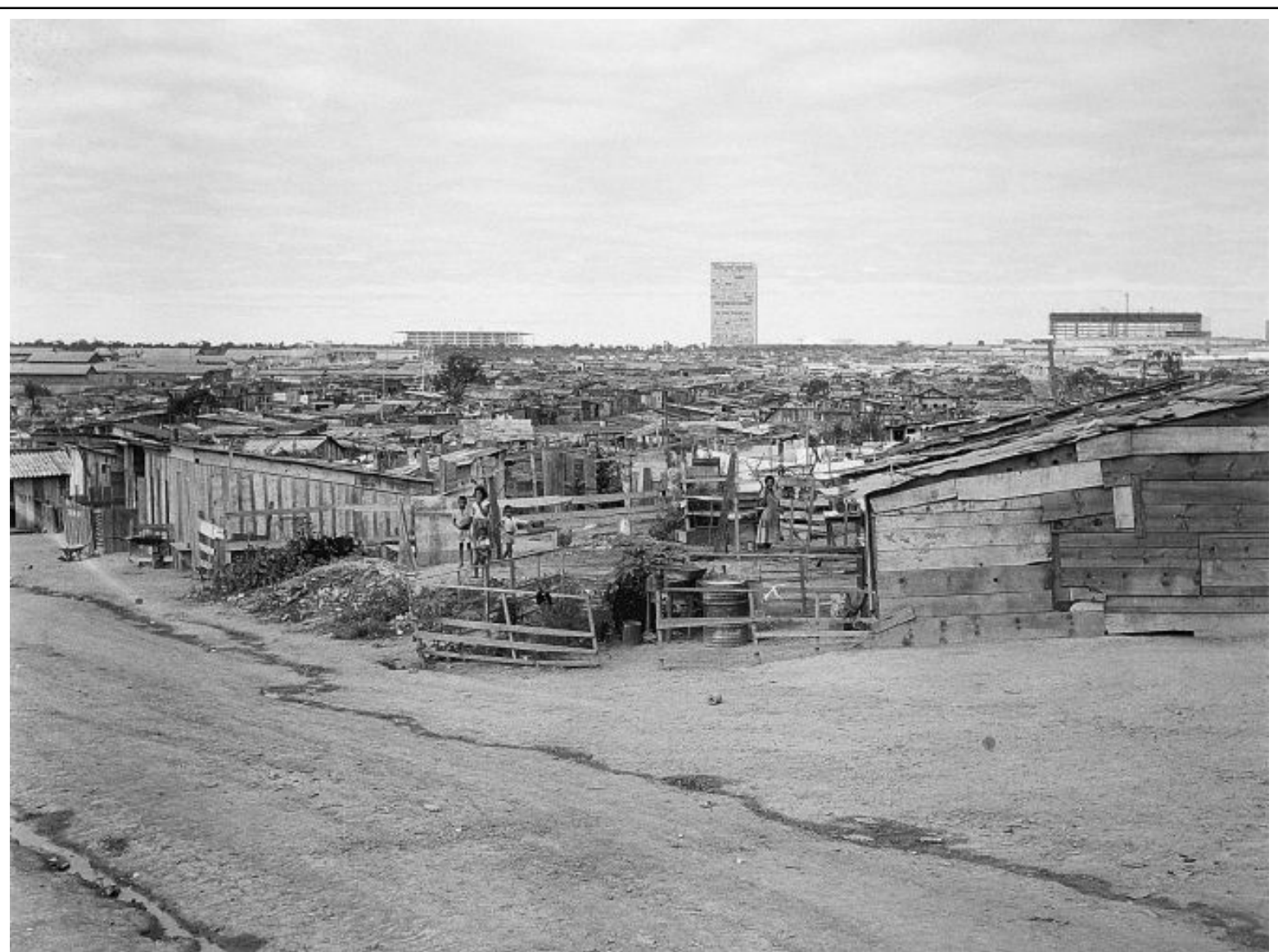

Figura 5 - Foto da Vila Amauri (Fonte: http://noticias.uol.com.br/album/100415brasilia50 album.jhtm\#fotoNav=40) 